\title{
Narrativa literária: suporte para a infância, texto para a juventude
}

\author{
Celia Abicalil Belmiro*
}

\begin{abstract}
Resumo
O livro de literatura infantil contemporâneo tem se constituído sobre o tripé: texto, imagem, formato do suporte para embasar a construção da narrativa. Todavia, esses elementos também podem falsear ou transformar o perfil das obras consideradas canônicas para crianças, explicitando a arbitrariedade desse modelo de livro. Por outro lado, narrativas que exploram o texto verbal e o texto visual pressupondo um leitor-modelo juvenil, e que mantêm um formato de livro infantil, indicam que essa faixa adolescente vem se constituindo como um leitor que utiliza linguagens múltiplas e simultâneas. Este trabalho analisa elementos-chave da narrativa no livro Nenhum peixe aonde ir, da autora franco-canadense Marie-Francine Hébert, com ilustraçôes de Janice Nadeau. O tema da guerra, sob os olhos da criança e sob uma forte presença da enunciação, permite diferentes camadas de leitura e compreensão. Ao mesmo tempo, usos de imagens, fontes de texto e diagramação, que outrora indicavam um leitor infantil, contemplam atualmente uma variedade de leitores de diferentes públicos e idades. A obra As margens da alegria, de Guimarães Rosa, com ilustraçóes de Nelson Cruz, tem o objetivo de contrapor algumas especificidades de composição visual e de texto. Categorias das artes plásticas (superfície, imagem) e da teoria da leitura (leitormodelo, pressuposição) ajudam a compreender esse fenômeno que se tornou modelo de letramento: o livro de literatura infantil. Dessa forma, a concepçáo de juventude e de leitura para o jovem vem sendo reavaliada para que sejam incluídas outras formas de texto e, nelas, a literatura.
\end{abstract}

Palavras-chave: Literatura infantil. Leitor. Ilustração.

\footnotetext{
* Doutora em Educação pela Universidade Federal Fluminense (UFF). Professora da Faculdade de Educação da Universidade Federal de Minas Gerais (UFMG).
} 


\section{Introdução}

O livro de literatura infantil tem se constituído, na sua história contemporânea, sobre o tripé: texto, imagem, formato do suporte. Esses três elementos embasam a construçâo da narrativa, indicando, para o leitor mirim ou para o mediador, a escolha do interlocutor privilegiado. Todavia, esses elementos também podem transformar o perfil das obras consideradas canônicas para crianças. As que não cumprem essa correspondência triádica explicitam a arbitrariedade desse modelo de livro que se constitui em um gênero específico. Por outro lado, narrativas que exploram texto verbal e texto visual pressupondo um leitor-modelo juvenil, e que mantêm um formato de livro infantil, indicam que essa faixa adolescente tem se caracterizado por um tipo de leitor que utiliza linguagens múltiplas e simultâneas.

Este estudo apresenta algumas reflexôes sobre o conceito de "jovem/ adolescente" para melhor compreender a diversidade atual de leitores e suas possibilidades de leitura. $\mathrm{O}$ intuito de aproximar criança, jovem e adulto como leitores possíveis da mesma obra fortalece a perspectiva de que os livros contemporâneos, tratando a discursividade e a plasticidade como partes integrantes da narrativa, possibilitam a exploração de um campo híbrido de linguagens, uma vez que é pela junçáo do verbal e do visual que o enredo se realiza.

A concepção de leitura, por conseguinte, deve ser reavaliada para que sejam incluídas outras formas de texto e, nelas, esse gênero literário "livro ilustrado". São analisados elementos-chave da narrativa no livro Nenhum peixe aonde $\mathrm{i} r$, da autora franco-canadense Marie-Francine Hébert (2006), com ilustrações de Janice Nadeau, em que textos verbais, visuais e seu suporte se mesclam em uma estrutura narrativa mais complexa, com aspectos discursivos e plásticos dando a ver uma consciência do contexto sócio-histórico amplo e uma reflexão sobre acontecimentos que marcaram a história da humanidade. $\mathrm{O}$ tema da guerra, sob os olhos da criança e sob uma forte presença da enunciação adulta, permite diferentes camadas de leitura. Ao mesmo tempo, usos de imagens, de fontes de texto e diagramação, que outrora priorizavam um leitor infantil, contemplam atualmente uma variedade de público e de idade. A obra As margens da alegria, de Guimarães Rosa (2010), com ilustrações de Nelson Cruz, tem o objetivo de contrapor algumas especificidades de texto e de composiçáo visual, sinalizando outras opções de realização. 
Ainda que, na sua origem, as obras analisadas tenham endereçamentos distintos - uma tradução de uma obra franco-canadense de 2003 para um público jovem e um texto brasileiro escrito em 1962 com adequação editorial para o público infantil em 2010 -, vale pensar como seus trabalhos foram elaborados, quais suas especificidades e saber que passaram pelo crivo de apreciação pública, através das avaliações da Fundação Nacional do Livro Infantil e Juvenil - FNLIJ - em 2007 e 2010, além do Programa Nacional Biblioteca da Escola - PNBE.

Categorias das artes plásticas (superfície, imagem), da teoria da leitura (leitor-modelo, pressuposição) e da filosofia da linguagem (interdiscursividade bakhtiniana) ajudam a compreender esse fenômeno que se tornou modelo de letramento, que é o livro de literatura infantil.

\section{Primeira parte: literatura para infância, literatura para jovens...}

São muitas as interrogaçóes que pesquisadores vêm realizando, desde as décadas de 1970 e 1980, na tentativa de explicar que gênero é esse e que livros são esses. Autores definem literatura infantil (literatura destinada a crianças) através de diferentes tendências e perspectivas (ABRAMOVICH, 1983, 1995; CADEMARTORI, 1986, 2009; CUNHA, 1983; SOSA, 1980; PERROTI, 1986, 1990; SANDRONI, 1987; ZILBERMAN, 1981, entre outros), ora observando o caráter externo ao texto, no nível das formas de edição e divulgação, ora propondo como base a análise do conteúdo, alguns ainda pensando o gênero como uma forma composicional que organiza uma maneira de pensar o mundo da imaginação, tomando uma faixa etária como indicação do limite e das possibilidades de experiência de leitura.

Algumas análises apoiam a discussão que se trava neste estudo. Gregorin Filho (2009, p. 15) acredita que

[...] uma literatura pode ser chamada de infantil apenas no nível de manifestação textual, isto é, no nível do texto em que o leitor entra em contato com personagens, tempo, espaço, entre outros elementos textuais; percebe-se também que os temas náo diferem dos temas presentes em outros tipos de texto que circulam na sociedade, como a literatura para adultos e o texto jornalístico, por exemplo. 
Essa adequação textual seria, entre outras possibilidades, a de uma linguagem simplificada, de valores temáticos destinados a um público infantil.

Peter Hunt (2010), por sua vez, traz uma discussão que pode ajudar a esclarecer algumas dificuldades do momento atual da crítica sobre o texto para crianças. Ele comenta que a

[...] "adequação" é julgada de maneira diferente por geraçôes diferentes e pelos que têm interesses diferentes. Disso decorre uma longa tradição de comercialização de mitos, lendas, contos populares e contos de fadas para crianças, em desafio a quase todos os padróes estabelecidos para o conteúdo dos livros para crianças. (HUNT, 2010, p. 289).

Com isso, Hunt (2010) nos propóe pensar que as diversas preocupaçóes adultas ou de um jovem no final de sua adolescência, inseridas num texto infantil, traduzem um mascaramento da voz imperiosa do adulto em relação às personagens infantis e às crianças leitoras. $\mathrm{O}$ autor acrescenta ainda que é nos livros para crianças que vemos, através de expedientes discursivos, uma verdadeira conspiração contra o mundo adulto, ainda que isso não represente verdadeiramente a visão infantil sobre o mundo.

Para este estudo, importa refletir sobre essa "adequação" contemporânea que torna fluida qualquer definição que enrijeça a experiência da produçáo literária ou de qualquer outra arte. Vale dizer, o que temos visto ultimamente de produção literária dirigida a crianças se tem apoiado em tantas outras linguagens, no aguçamento de sensaçóes táteis, olfativas, visuais, sonoras, que a obra literária para a infância (ou a sua definição) ultrapassa o relato verbal. Não é suficiente apenas a adequaçáo textual ao tipo de leitor, como também não bastam preocupações de ordem histórica ou política na inserção da obra, mas deve-se destacar o modo como é problematizado o tema, caracterizando um discurso e uma plasticidade que organizam um olhar sobre o mundo; muitas vezes de cunho educativo e ideológico, as obras constroem uma visão de criança e estão mais interessadas na formação moral dos sujeitos do que propriamente em elaborar relaçốes com o imaginário ou mesmo tentar espelhar o olhar infantil.

A relação da literatura infantil com o conceito de infância vem organizando um quadro cada vez mais vago e esgarçado, uma vez que questôes de ordem social, histórica e tecnológica produzem novas estratégias 
de interação, de hibridização de linguagens e de exploração de capacidades cognitivas diferenciadas num mesmo suporte. Convém, todavia, aprofundar ainda mais as pesquisas sobre as relaçóes da criança e o livro de literatura, ou atentar, antes, para a afirmação de Hunt (2010, p. 255) ao denunciar que "[...] existe uma interação complexa não só entre a criança e o livro, mas entre a criança e a idéia de livro [...]". Isto permite perguntar também qual a ideia de livro e de criança que autores, ilustradores e editores constroem ao lançar obras "destinadas" às crianças. Muitas delas apresentam o terror e o medo como tema a ser desenvolvido, e náo como pano de fundo para o controle dos sujeitos mirins. Obras como Pequenos contos para sentir medo: histórias tradicionais de muitos lugares, de Christine Palluy (2011), tradução de Heloisa Jahn, é um dos vários exemplos que buscam aproximar o universo ficcional do universo infantil, construindo experiências de formaçáo. A obra seminal de Maurice Sendak (2012) Onde vivem os monstros, de 1963, percorre o tempo com uma proposta sempre atual.

As inquietaçóes contemporâneas a respeito dos condicionantes de um tipo de literatura infantil sáo discutidas por Cademartori (2009), que aponta a mudança de foco dos anos 1970 para os dias atuais, quando o gênero se expande e se consolida, enfatizando a diferença e o respeito pelo lugar do outro.

A identidade, parece que finalmente aprendemos, não é fixa, mas mutável. Não nascemos com ela. Nós a construímos ao longo da vida vivida, pensada, sonhada, compartilhada. Por isso, uma forte vertente temática da literatura infantil contemporânea volta-se ao reconhecimento de diferentes grupos sociais como sujeitos portadores de uma cultura. (CADERMATORI, 2009, p. 53).

Os que antes eram personagem da ficção, apenas integrantes de um texto autoral, assumem a palavra da enunciação, protagonizando a narrativa e tornando-se porta-voz de seu grupo social e cultural.

\section{De qual leitor estamos falando?}

Tradicionalmente, a discussão sobre a literatura destinada a crianças e o texto literário destinado a adultos pretende realçar uma certa definição de 
literatura, ou a especificidade do interlocutor mirim que ainda não desenvolveu certas capacidades cognitivas - ou ainda não viveu profundas experiências humanas. A polaridade entre esses dois universos é exemplar do modo como compreendemos o mundo. A distância entre esses dois universos estaria no aprofundamento da temática, conforme alguns pesquisadores. Para Nikolajeva e Scott (2011, p. 39), muitos trabalhos em livros ilustrados dedicados à infância, à primeira vista, se caracterizam pela "tripla audiência", "[...] destinados a crianças pequenas, jovens e adultos sofisticados, comunicando-se em diversos níveis com ambos os públicos". Muitas vezes, as convençôes da escrita alfabética inibem a liberdade de uma leitura mais liberta e, contudo, arguta das crianças.

Todavia, outros sujeitos sociais vêm marcando um espaço de subjetividade e devem interessar aos que procuram compreender as formas de arquitetura dos textos e sua destinação. Assim, cabe interrogar quem são esses outros sujeitos que emergem dos textos, mas que, em alguns casos, ainda não são percebidos com nitidez suficiente. Essas escritas têm sugerido outras experiências de leitores, os adolescentes.

Diferentes áreas do conhecimento, como a Sociologia, a Psicologia, a História, dentro do âmbito da Educação, vêm propondo a construção do conceito - o jovem (ou o adolescente) -, ainda que haja uma tendência também universalizante e, por isso, redutora, para seu entendimento. Porém, a ideia de dar existência a alguma outra instância entre a infância e a fase adulta nos leva a pensar que os textos de literatura para jovens devam apresentar temáticas e tratamento temático e discursivo que repercutam as dificuldades e anseios desses leitores.

Pesquisadores, a exemplo de Corti e Souza (2004), e Dayrell (2007), que se dedicam a compreender esse contexto, procuram definir ou, pelo menos, iluminar o campo, buscando a compreensão de juventude como categoria social e histórica: adolescência/juventude/adolescente/jovem. Desde a sociedade camponesa, atravessando a sociedade medieval, até a sociedade moderna e pósmoderna, a concepção de ser jovem mostra sinais ambíguos de categorização, ora por faixa etária, ora por capacidade produtiva ou por função social. Embora o Estado Moderno tenha modificado o papel dos jovens na sociedade, foi no século XIX e, principalmente, no século XX que os traços da condição juvenil foram amplamente difundidos. Deve-se ressaltar que a modernidade calcou esse conceito baseado nas classes altas e médias, excluindo de seu repertório problemas provenientes de setores populares. Corti e Souza (2004), pesquisando 
acerca das definiçōes de adolescente /jovem e adolescência/juventude, não veem qualquer distinção entre os termos e preferem trabalhar com a definição de adolescência como a primeira fase da juventude, justificando que essa última também possui diferenciações internas relacionadas ao desenvolvimento psíquico, fisiológico e social dos sujeitos em seus diferentes estágios. Comentam ainda que

Atualmente, vivendo em plena modernidade (que alguns preferem chamar de pós-modernidade), percebemos que as características mais marcantes da concepção de juventude vigente são sua fluidez e complexidade. Esta concepção está em constante transformação e disputa nas sociedades ocidentais. Não se trata por isso de algo acabado, mas sim de um processo dinâmico de construçáo de significados ainda em curso, que envolve as representaçôes que a sociedade possui dos jovens, mas também a percepçáo dos próprios jovens sobre sua condição. (CORTI; SOUZA, 2004, p. 19).

De ser alguém "à espera de" (um período "preparatório" para a fase finalmente adulta), os jovens passam a ser indicadores de um modo de ser contemporâneo e passam a ditar moda. É uma atitude, um modo de estar no mundo.

Dayrell (2007) amplia essa discussão, relativizando o conceito de juventude como uma categoria dinâmica, que se transforma social e historicamente. Mais do que juventude, ele prefere tratar os jovens como sujeitos que experimentam a juventude num determinado contexto sociocultural em que se inserem. Por isso, escolhe trabalhar com a ideia de "condição juvenil":

Assim existe uma dupla dimensão presente quando falamos em condição juvenil. Refere-se ao modo como uma sociedade constitui e atribui significado a esse momento do ciclo da vida, no contexto de uma dimensão histórico-geracional, mas também à sua situação, ou seja, o modo como tal condição é vivida a partir dos diversos recortes referidos às diferenças sociais - classe, gênero, etnia, etc. (DAYRELL, 2007). 
Dessa forma, além da dimensão biológica que se universaliza, a existência de uma determinada condição juvenil é que vai influenciar a experiência escolar e os sentidos a ela atribuídos. O autor relativiza tanto o conceito de jovem, preferindo jovens, juventudes, no plural, quanto o de escola, cuja realidade nâo é monolítica, mesmo sendo uma instituição com normas e regras de unificação e delimitação das açôes dos sujeitos: alunos, professores, funcionários, pais são promotores de alianças e conflitos, constituindo um movimento de apropriação constante de espaços, normas e práticas que dão forma à vida escolar. Acrescenta ainda tensão à discussão, na medida em que esses jovens, ao entrar na escola, passam a ser alunos, uma construçáo histórica, com uma determinada ordem social, conformando um modo de vida específico:

Assim o jovem se torna aluno em um processo no qual interferem a condição juvenil, as relaçóes intergeracionais e as representaçôes daí advindas, bem como uma determinada cultura escolar. Acredito ser aqui, na forma como os jovens vêm se constituindo como alunos, que reside um dos grandes desafios na relação da juventude com a escola, colocando em questão velhos modelos, com novas tensóes e conflitos. (DAYRELL, 2007).

Os impasses que os jovens vêm vivendo na sua transição para a vida adulta mostram a convivência com funçóes próprias da vida adulta e, ao mesmo tempo, situações de dependência (SPOSITO, 2002).

O que interessa ao presente estudo é fazer o percurso contrário e pensar que esse período, visto como de transição, não afeta somente as relaçóes dos jovens com os adultos, tomados como um horizonte de perspectivas a partir do qual os mais novos devem se situar em relação ao seu futuro, também interfere na articulação das produçóes literárias destinadas aos jovens com as produçóes voltadas para a infância. Ou melhor, como se aproximam as diversas produçóes, num trânsito de leitores e de leituras em diferentes níveis.

Um fator relevante para o presente debate é a presença da multimodalidade de linguagens de que os jovens se apropriam para falar, ouvir, ler e escrever o mundo que para eles têm significado e os significam. A liberdade de usos de imagens nos livros de literatura infantil, dirigidos a leitores iniciantes e que, por isso mesmo, justificam ter o apoio das linguagens visuais para melhor compreender os significados da narrativa, se estende, no momento atual, para as 
produçōes juvenis, incorporando o diálogo entre o texto verbal e o texto visual como forma de construir significados no campo da literatura. Diferentemente das revistas em quadrinhos, que já conquistaram lugar no mundo da leitura infantil, juvenil e adulta (pensando, a partir de Nikolajeva e Scott (2011), em tripla audiência), das charges que são largamente usadas em livros didáticos de todos os níveis de ensino, os livros literários para jovens vêm incorporando linguagens variadas (grafites, ícones, gêneros textuais diversos), num conjunto novo que repercute o contexto contemporâneo de comunicação.

$\mathrm{O}$ amálgama de lugares e tempos que define esses sujeitos, os jovens, suas condiçóes socioculturais e seus contextos específicos repercutem na liberdade de propostas de produção de livros de leitura e de leitura literária a eles destinados. São muitas obras clássicas, como as de Machado de Assis, A divina comédia, de Dante, Don Quixote, de Cervantes, entre outras, adaptadas para os quadrinhos, ao lado de longas histórias de vampiros envoltas em contos de amor, narradas somente com texto verbal, além de uma infinidade de obras que mesclam linguagens e gêneros, retextualizando, na mídia impressa, a rapidez dos clips musicais.

Alguns indicadores merecem ser destacados de forma a pensar, por um lado, até que ponto as obras de literatura para jovens estáo se apropriando das características discursivas e plásticas de obras para a infância e o que isso pode significar; por outro lado, como as abordagens multimodais têm tido prioridade nas produçóes contemporâneas dedicadas a crianças e jovens: 1) a presença irreversível da visualidade como linguagem de expressão, e oferecida à compreensão do leitor, predominante no contexto contemporâneo e midiático; 2) a diversidade e pluralidade cada vez maior de livros que exploram a linguagem do ponto de vista textual, discursivo e plástico; 3) a categoria indefinida ainda de "jovem" e sua construçấo carecendo de um espaço específico de pertencimento; 4) a fluidez e a complexidade como características fundantes da adolescência/ juventude; e, finalmente, 5) a tendência da produçáo de graphic novels a partir de textos clássicos como mais um caminho de inserçáo no mundo da leitura literária.

Um aspecto demonstrativo dessa margem flexível e indefinível em que se situam os "jovens" é o trabalho de algumas instituiçóes que desejam colaborar com diferentes categorizaçóes para o enquadramento de obras. É o caso da Fundação Nacional do Livro Infantil e Juvenil - FNLIJ, do Plano Nacional de Biblioteca Escolar - PNBE, entre outros, que vêm alargando suas categorias de 
análise com vistas à classificação dos livros e propondo algumas novas soluçōes para tentar dar conta da produção atual. Dirigido a crianças, o formato livro infantil parece ter uma estrutura definida ou, pelo menos, reconhecida, pelo tamanho de folha, quantidade de textos, de letras, imagens, cores e uso do espaço para a construção da narrativa. Todavia, não há uma tendência específica para livros destinados a adolescentes, ainda que a exploração de diferentes temáticas com personagens jovens venha marcando um tempo de grandes mudanças na construção social desses sujeitos, no âmbito da produção literária contemporânea. Interroga-se, então, por extensão, quem são esses leitores adolescentes que se situam entre a leitura dita adulta e a leitura de textos com recursos característicos de trabalhos para a infância. Por outro lado, saber que leituras são essas e como se processam nos conduz a uma última questão que se torna, nos dias de hoje, o termômetro para muitos programas de avaliação de leitura e de leitores: o que é ler nos dias de hoje?

Mascara-se a pluralidade ao se fazer referência a um leitor universalizado, uma vez que aqui não se leva em conta apenas a produção, mas o que seu discurso pode produzir. E em quem. Artigos de crítica, textos acadêmicos, catálogos de editoras, referências bibliográficas ainda apresentam abordagens analíticas e modelos de catalogaçấo que separam a literatura adulta das demais, por isso mesmo chamadas de "infantil e juvenil" ou infanto-juvenil, como um sintagma que generaliza e exclui e as riquezas características desses períodos da vida.

\section{Segunda parte}

A consideração de que os leitores são múltiplos e de que as obras atravessam idades, sendo lidas por crianças, jovens e adultos, renova o campo de análise dos aspectos discursivos, plásticos e formais do livro ilustrado. Alguns termos vêm sendo elaborados para indicar a transgressáo de limites que novos gêneros estão propondo. A expressão "livro ilustrado" ${ }^{1}$ serve para definir duas diferentes tendências na produção editorial mundial, a saber, o livro com ilustraçóes e o livro cujas imagens participam da construção da narrativa, sendo consideradas como elemento discursivo. O conceito de crossover $^{2}$, termo cunhado para explicitar a tendência atual de um novo modo de reconhecer a audiência, o texto, o discurso, enfim, o fenômeno literário, é uma demonstração da consideração de que os livros ilustrados podem ser lidos por diferentes faixas etárias, cada uma percebendo, a seu modo, as entrelinhas, as ironias, as 
intertextualidades. Exemplo disso são os livros elaborados por artistas plásticos que desenvolvem narrativas com imagens e textos ou apenas com imagens, para crianças pequenas e que muitas vezes cativam adultos; os livros cujos textos verbais fazem referência e comentam obras de arte, destinados a crianças e jovens e que repercutem o contexto artístico e cultural de uma certa época; ou aqueles que tratam de temáticas que atravessam idades, sejam experiências pessoais ou coletivas.

A intenção das análises a seguir é dialogar com a perspectiva de trânsito entre linguagens, entre idades, entre projetos editoriais que circulam na sociedade.

\section{Intersemiose e a hibridização de linguagens}

Nenhum peixe aonde ir, texto de Marie-Francine Hébert e ilustraçóes de Janice Nadeau, com tradução de Maria Luiza Borges, editada pela SM Ediçóes, é uma obra premiada pela FNLIJ em 2007, produção 2006, na categoria "Tradução/Adaptaçáo jovem". À primeira vista, o livro contém todos os elementos geralmente dirigidos à infância: texto, imagens, cores e uma narrativa composta pela imbricação de texto/imagem. Além disso, o tamanho e formato da folha, grande e na vertical, estão fora dos padrōes frequentes de edição para jovem ou adulto. Outro aspecto que compóe o conjunto de elementos que tradicionalmente se destinam ao livro para a leitura infantil é a fonte e o espaçamento entre linhas, que dão conforto ao leitor iniciante. Ora, restrita a esses elementos, a obra poderia ser entendida como endereçada ao leitor mirim.

Todavia, a análise da temática e da construção da narrativa mostra uma história dentro da outra, um livro sendo lido pela personagem, como uma metaficção que atravessa e compóe as camadas de leitura. Assim, pode-se perguntar: qual livro: o que o leitor tem nas máos ou o que a personagem da história lê? Qual história ou quais histórias? O que dizem as imagens (ilustraçôes?) que narram outra história? Qual o fio narrativo que o leitor deve perseguir? Para iniciar a análise desse livro, deve-se atentar para quantas histórias esse suporte tem ou: mais do que imbricação, como se dá a relação de histórias que o leitor tem em mãos? Na folha de rosto, apresentam-se dois títulos: Nenhum peixe aonde ire $O$ pote dos sonhos. Qual deles é a pista para iniciar a leitura? Tal complexidade narrativa indica o caráter polissêmico do texto, e solicita um leitor atento e habituado a conviver com diferentes estratégias de 
leitura para a produção de sentidos. Percebem-se algumas instâncias narrativas: a que conduz o leitor pela história Nenhum peixe aonde ir; a que orienta o leitor para a compreensão de $O$ pote dos sonhos, com citação de trechos no interior da narrativa principal; e a apresentação física do livro $O$ pote dos sonhos, com seleção de trechos de texto e ilustração. Com o discurso indireto livre, ao mesmo tempo assumindo um ponto de vista da garota protagonista, o narrador desenvolve uma percepção crítica do mundo que se mescla ao olhar infantil: "Por que então sua voz está tão aguda? Por que parece que ela está sem ar, grudada ao bebê, que nem se lembra mais do mingau? Por que seu olhar parece perdido no bosque do desaparecimento?". Ou: "Mamãe não vai gostar, papai também não. Os homens mascarados vão reclamar. Zolfe imagina o pior". Mais adiante, história dentro da história, o peixe e o pote (figura 1): "Caminham sem conseguir enxergar nada, como se tivessem esquecido também os olhos. [...] uma urna de contornos estreitos [...] descobrir o seu tesouro".

Figura 1 - Nenhum peixe aonde ir

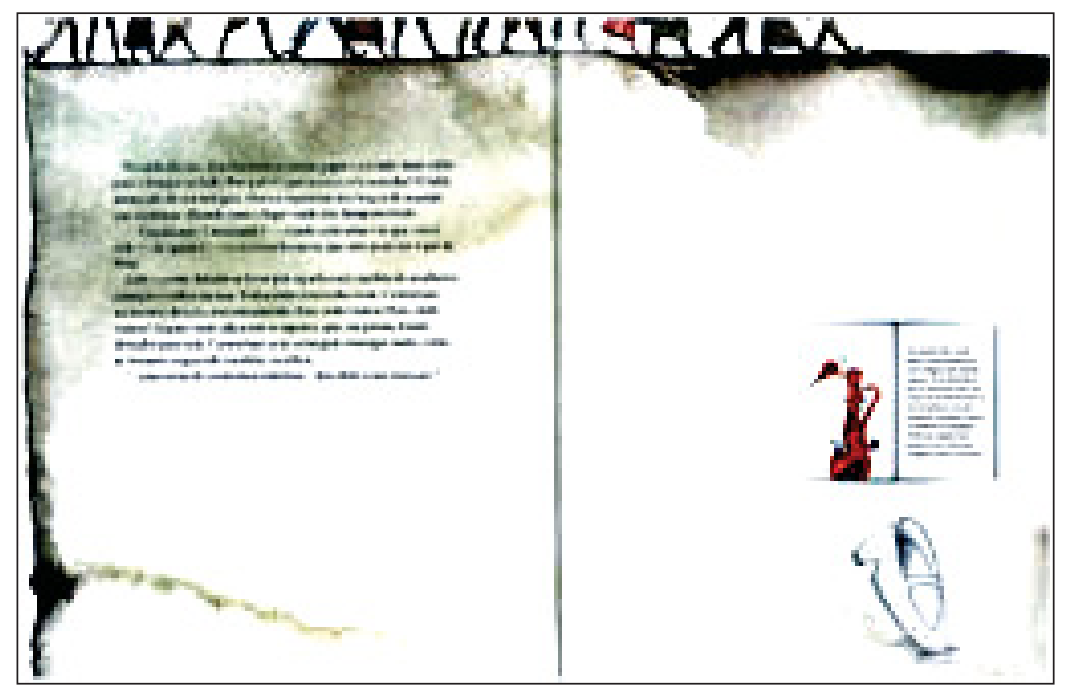

Fonte: HÉBERT, 2009. 
Figura 2 - Nenhum peixe aonde ir

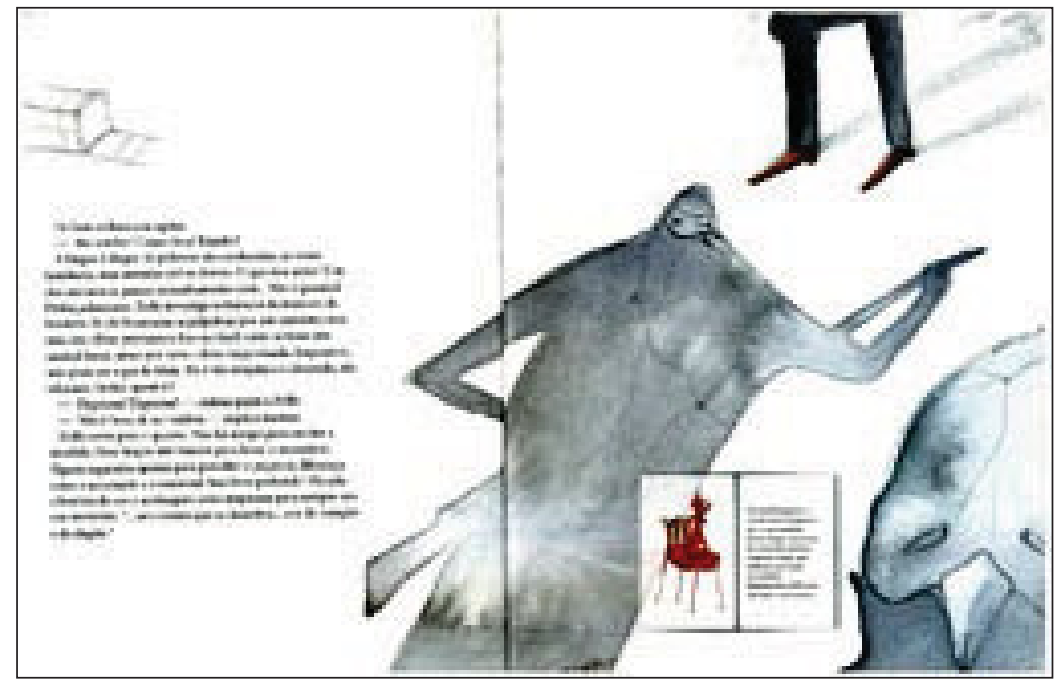

Fonte: HÉBERT, 2009.

Figura 3-Nenhum peixe aonde ir

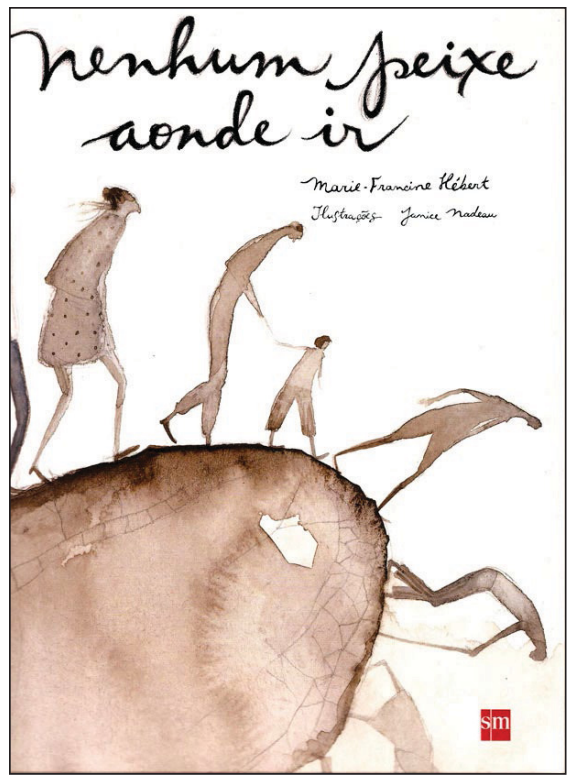

Fonte: Capa HÉBERT, 2009. 
Essa fragmentação da linearidade narrativa, que espelha as tensões da experiência humana e com que se intui a complexidade do momento histórico retratado na história, tem nas imagens uma das principais fontes de expressão, de contextualizaçẫo e de indagação. Como componente da enunciação, o diálogo imagem/texto verbal é um dos fundamentos da proposta da obra: visto como aqueles que não dominam seu destino, que verdadeiramente o perderam, os personagens que marcham com Zolfe, a menina protagonista, não têm rosto, não têm corpo inteiro, só metade de corpos, pedaços de braços, de pernas, uma alegoria dos homens que perderam sua identidade, sua distinção.

Por outro lado, os mascarados, sim, eles são inteiros e atiçam os outros homens num caminho sem fim, a esmo - para quem vai -, embora com direção certeira - para quem ordena caminhar (figura 2). Todavia, são deformados, sem cor (ou cinza, que repercute um mundo preto ou branco, bem ou mal, totalitário, enfim), pequena cabeça de pássaro, distante do formato humano. Analisando as ilustraçôes em livros para crianças pequenas, Hunt (2010) relativiza algumas teorias que afirmam que as imagens ali contidas pretendem trazer o mundo tal qual ele é, como "retratos literais". Lembra que "[...] é evidente [...] que, mesmo em um estágio bastante avançado de socialização, as crianças percebem as coisas de modo diferente dos adultos; no entanto, paradoxalmente, pode ser que com o livro ilustrado adultos e crianças estejam em seu ponto de maior proximidade" (HUNT, 2010, p. 236).

Essa é uma manifestação das possíveis interações entre linguagens, discursos e interlocutores, que se articulam fora de interpretações restritivas. Ainda que vinculadas a uma análise de livros ilustrados para crianças de Educação Infantil, a afirmação do autor aproxima adultos e crianças, e (implicitamente?) os jovens. Assim, o signo que indica um ser não pensante, sem consciência da importância de sua ação política no mundo e de sua humanidade, é a representação de uma cabeça pequena, bico e máscara. Defendendo Sendak, ao ser acusado de não conhecer as proporçóes do corpo humano e desenhar figuras grotescas de crianças com cabeça grande, Hunt (2010) alerta para as características de organização espacial e dos objetos no espaço infantil. No caso do livro Nenhum peixe aonde ir, a escolha do tamanho das cabeças pode sinalizar as condiçôes de compreensão das crianças, e também um olhar mais adulto para engendrar essa construção simbólica: cabeça pequena, sinal de pouco siso. Em contrapartida, deve-se lembrar que o uso da ilustração na capa (e, neste caso, sua disseminação para a quarta capa) tem origem nas produçôes 
para crianças (POWERS, 2008), o que mostra esse constante aproveitamento do caráter simbólico da espacialidade da folha. Tanto para a infância quanto para os jovens, a obra se abre em procedimentos amplos que absorve múltiplos olhares, múltiplos leitores. Já há muitas décadas, vê-se a difusão do uso de capas sugestivas na maioria das edições, sejam elas destinadas às crianças, sejam a jovens ou adultos. Isso indica que, independentemente da faixa etária, certos procedimentos que exploram a intersemiose se tornam significativos e assimilados pela população em geral como uma habilidade cognitiva.

A radicalidade do uso do espaço da folha compóe magistralmente o contexto da temática e ajuda na condução narrativa. Apresentada sempre em página dupla, abertura inteira do objeto livro que se oferece para leitura, a narrativa assume a espacialidade como participante da história. Já na folha de rosto, são apresentados autor, ilustrador, tradutor, dedicatória, o título da história e o título do livro lido pela menina no interior da história. Porém, os personagens que fazem parte da história do livro ilustram o livro que a menina tem em mãos. Consequentemente, onde se situam as histórias? Oferece-se, assim, logo de início, uma tensão narrativa na obra Nenhum peixe aonde ir (HÉBERT, 2006), obrigando o leitor a uma postura de interrogação.

O conceito que pode e deve ser analisado nesses suportes é o de representação do espaço. A profundidade de campo, que cria, na Renascença, uma nova forma de organização do mundo, é substituída pelo olhar do homem do século XXI, que vê, por imagens, um mundo reproduzido via satélite e impossível a olho nu. Esse sujeito não está mais dentro do mundo para recortá-lo com sua lógica matemática, o vê de fora, numa visão totalizante dada pelo holograma ${ }^{3}$. A realização de filmes em 3D é um bom exemplo de reconstruçáo de formas de representação, o que reflete as estratégias do homem de se aproximar do mundo, dele participando virtualmente. Vale lembrar que o grande espectro de perspectivas que abarca o tema dessa discussão tem na sua base o conceito de ilusionismo, tantas vezes revisto e sempre em tensão. De qualquer forma, Kac (2006) esclarece que esse termo nunca significou que o espectador seria enganado por uma imagem e pensaria estar olhando para o objeto mais do que para uma representação. Hoje, diante da irrealidade proposta pela realidade pós-moderna, já se reconhece a dimensão ilusionista não como um mimetismo, porém algo destoado e recriado por imagens sem fundo, sem margem, sem preenchimento. No mundo atual, os homens não precisam decifrar mais a mensagem divina e, sim, a dos próprios homens, 
transformada em ciência, em arte, em virtualidade. Vale lembrar os estudos de Gombrich (1986), para quem os mecanismos psíquicos de que dispomos nos fazem compreender organizadamente os elementos de alguma imagem dentro de um dado contexto cultural, mesmo que saibamos ser uma ilusão. Presença e memória, marcas da inteligibilidade humana, acompanham a ordem do suporte.

Na primeira página dupla da obra (HERBERT, 2010), a materialidade do enunciado visual é oferecida pela aquarela, técnica que tem um tempo próprio de ação; é preciso esperar que a tinta aquarelada escorra pelo papel para ver o que ela oferece ao expectador. Seu limite, portanto, não é dado pelas máos do artista, que pode criar formas com precisão, porém pelo tempo do esvair das cores no papel, seu próprio devir. O uso desse procedimento corrobora a temática, a falta de contornos definidos das formas compóe o mistério que cerca o contexto histórico das personagens, enfim, uma época de incertezas, dúvidas e mistério.

A liberdade do artista no uso da página dupla reforça a dimensão semântica da organização visual do cenário. Signos de opressão e de perda de identidade, os seres caminham excluídos do enquadramento do cenário (figura 1), fora da margem, mas ainda dentro da folha, assinalando a tensão que constitui esse drama. As pessoas são só uma marcha sem sentido, sem direção, sem precisão: "Zolfe e a mãe deixam-se levar por aquela onda insólita de mulheres, crianças e velhos na rua. Todos estão irreconhecíveis. Caminham na mesma direção mecanicamente. Para onde vamos? Para onde vamos?” (HERBERT, 2010). Da mesma forma, a urbanidade que emerge da organização social das cidades é a representação da destruição e da fragmentação dos terrenos: casas e utensílios desmoronam, a vida da cidade é esfacelada: "Impossível procurar refúgio entre os pais ou os amigos, suas casas estão vazias, também abandonadas às pressas. $\mathrm{Ou}$ as cortinas estão puxadas e as persianas fechadas. Em pleno dia" (HERBERT, 2010). A grande questão para a menina Zolfe é saber que seu destino e o dos seus parentes e amigos estão sendo traçados por mãos fortes e alheias à sua vontade. "Onde eles dormirão esta noite? Não vale a pena perguntar a mamãe. Zolfe sabe muito bem que não tem nenhum peixe aonde ir. 'Nenhum lugar, quero dizer... nenhum lugar aonde ir". (HERBERT, 2010).

"Circulando! Circulando!" é a ordem que recebem e que é retratada no movimento inteiro da página como um círculo vicioso, um sem-fim de lugar nenhum (capa, quarta capa e interior da obra (figura 3). Náo é à toa que essa 
imagem é a que está estampada na capa. Pois é esse o sentido dado ao círculo, um elo fechado "[...] cuja compreensão está fora de alcance... Um pote cheio de escuridão” (HERBERT, 2010).

O conceito bakhtiniano de interdiscursividade explicita esse cruzamento de enunciados que, por sua própria natureza, são atravessados por diferentes vozes (BAKHTIN, 2000). Os elos intrínsecos entre o discurso imagético e o discurso verbal atuam na orientaçáo de leitura e abrem um horizonte de possibilidades interpretativas.

Apenas Zolfe se destaca pela cor, pelo porte e pela atitude. $\mathrm{O}$ uso das cores explicita um código de leitura situando as personagens-tipo, como os homens do mal (cinza), os seres humanos que obedecem sem levantar rosto (marrom), Zolfe e a amiga, estas, sim, azul e vermelho, destacando-se como pessoas que fazem avançar a história, que imaginam um lugar no mundo onde os sujeitos possam sonhar, um lugar para o peixe e seu aquário, "um lugar aonde ir".

As margens que definem os enquadramentos, que dão a ver os espaços de poder dos papéis sociais, estão irreversivelmente ultrapassadas. Tudo está fora do lugar. É assim que a presença das cores e dos traços constitui o campo simbólico do abandono. Em meio a essas cenas, o livro $O$ pote dos sonhos continua a ser folheado, segue a sina de se contrapor à realidade trágica, com suas histórias do maravilhoso mundo do senhor Fée, o ceramista, que faz com que a cada dia o seu objeto se transforme em urna, em vaso, em cujo interior se acha uma varinha mágica. E será dentro dele que a heroína da história do livro $O$ pote dos sonhos terminará por viver e se proteger.

Narrativa dentro da narrativa, enunciaçóes que se mesclam e que denunciam a complexa rede de tensôes dramáticas, a obra Nenhum peixe aonde ir (HÉBERT, 2006) abarca uma variedade de leitores e níveis de leitura, atendendo também a um público maduro que se dispuser a compreender as dificuldades de um povo, das gentes atropeladas pelo autoritarismo e pela guerra.

Por outro lado, a obra As margens da alegria compóe-se do texto de Guimarães Rosa (2010) publicado em 1963, com ilustraçóes posteriores de Nelson Cruz em 2010. É uma linguagem opaca que não prescinde de uma leitura qualificada para penetrar no mundo roseano. Premiado pela Fundação Nacional do Livro Infantil e Juvenil em 2011 - produção 2010 na categoria Criança, essa obra é exemplar da complexidade conceitual a respeito da literatura destinada a crianças. 
Uma série de expedientes dá forma a um produto que vem sendo definido como infantil: o formato é retangular, com uma leve orientação para o horizontal, a quantidade de texto em cada página está em equilíbrio com as ilustrações que dialogam com o texto, e a diagramação da página atende às expectativas de leitura. A temática também se insere no contexto infantil, e a estrutura narrativa ajuda a inserir os personagens e os diversos recursos em uma história de estripulias, ódio e alegrias: um menino, uma viagem de avião com os tios, uma casa perto do mato e a relação com bichos. O trabalho de visualidade da obra acompanha a qualidade do texto verbal, criando uma ambiência verbovisual de encantamento e sentimentos diversos de tristeza, amor, alegria, na contradição entre o erguer uma cidade e a morte das árvores, dos bichos, e a emoção de tudo ver.

A singularidade do texto de Guimarães Rosa (2010) instiga o ilustrador a descortinar imagens igualmente poéticas. As ilustraçóes de Nelson Cruz são de um rigor técnico e de uma sensibilidade plástica que fazem conjugar texto e imagem na direção da emoção e da fruição estética.

O projeto editorial utiliza com abundância páginas duplas, ora dimensionando a grandiosidade do projeto de construçáo da cidade (figura 6), ora conduzindo o leitor, através das ilustraçōes, de uma página a outra, da esquerda para a direita (figura 4). Em alguns momentos, as ilustraçōes penetram no espaço em branco destinado ao texto verbal, rompendo com o enquadramento natural dado pelo corte da folha; em outros, é o texto que permanece único na página. Essa dinâmica de leitura pelo uso móvel da espacialidade realça os movimentos narrativos do texto de Guimarães Rosa que são regidos pelos sentimentos do menino: "[...] o menino fremia no acorçoo, alegre de se rir para si, confortavelzinho, com um jeito de folha a cair". (GUIMARÃES, 2010, p. 4); "Assim um crescer e um desconter-se - certo como o ato de respirar - o de fugir para o espaço em branco. O Menino". (GUIMARÁES, 2010, p. 4). Pelo fato de as personagens não terem nome, a sua presença se realiza pelo corte dos rostos (figura 4), à exceção do menino protagonista. Em algum momento, a Tia é retratada na posição frontal com os cabelos encobrindo suas feiçóes (figura 7).

A liberdade do ilustrador em propor, por metáforas visuais, seu diálogo com o texto verbal, acrescentando-lhe sua leitura, dá a certeza de que a obra a ser lida não se constitui de uma só linguagem, mas as duas juntas, produzindo, na leitura, um efeito plástico-discursivo especial. A relação do menino com a mata é fundamental no conto, destacando o escuro, o medo, a curiosidade 
e a insegurança que fazem crescer o pequeno ser. "A mata, as mais negras árvores eram um montão demais; o mundo" (GUIMARÁES, 2010, p. 20). Essa é a imagem da capa: o menino em pé na janela vendo o mundo, que é a mata. O mundo visto pela janela é uma referência explícita ao conceito de enquadramento, que traduz a ideia dos olhos como janela da alma. A janela para o mundo, enfim, é símbolo do olhar do menino, cuja percepção de mundo vai, aos poucos, se constituindo e construindo esse sujeito.

O ponto de vista de quem vê a cena da criança olhando para o peru, aparentemente um olhar neutro, na verdade repercute o sentimento de deslumbramento do menino diante do animal que lhe abre as penas como numa elegante apresentação de si. "Tinha qualquer coisa de calor, poder e flor. Um transbordamento. Sua ríspida grandeza tonitruante. Sua colorida empáfia. Satisfazia os olhos, era de se tanger trombeta. Colérico, encachiado, andando, gruziou outro gluglo. O Menino riu, com todo coração. Mas só bis-viu. Já o chamavam para o passeio" (GUIMARÁES, 2010, p. 8). Por isso mesmo, o animal está em primeiro plano, uma figura imponente em relação à criança extasiada ao longe, ambos emoldurados pela natureza grandiosa. O contraste com a página em que ele sofre quando toma consciência da morte do peru (fig. 5) é exemplar do diálogo entre o discurso visual e o discurso verbal. Um vazio doído por dentro, um vazio chapado, mas cheio de significado, por fora pela inexistência de cenário, destacando apenas a presença do menino e uma pena, como sinal da ausência do bicho. "O peru - seu desaparecer no espaço. Só no grão nulo de um minuto, o Menino recebe em si um miligrama de morte" (GUIMARÃES, 2010, p. 11).

Considerando que esse gênero, o livro ilustrado, está aberto a múltiplas leituras, a obra mantém a fonte das letras em tamanho tradicional, sem a canônica apresentação em letras grandes para conforto visual ao gosto dos leitores mirins. $\mathrm{O}$ fato de o protagonista ser um menino, como se sabe, não justifica o enquadramento imediato da obra na categoria criança. Essa discussáo se torna fora de lugar na medida em que a generalização da categoria "criança" faz dissolver a intensidade da enunciaçáo adulta que olha para o menino, e intenta traduzir o sentimento infantil e sua percepção do mundo. Isso é que faz ultrapassar o simples enredo para dar a ver toda a experiência humana em forma de literatura. O estilo, a forma composicional, o vocabulário do texto verbal, juntamente com as imagens que organizam um modo de olhar e de apresentar os eventos do enredo, constroem um discurso verbovisual cujas características 
permitem diferentes entradas de leitura. Agregam-se, por um lado, a capacidade infantil de responder positivamente a discursos novos e imprevistos, oferecidos por um trabalho literário de qualidade, por imagens inesperadas e criativas, $\mathrm{e}$ de construir significados além dos que lhes são oferecidos na e pela educação escolar, geralmente com finalidade pedagógica e moralizante; por outro lado, é certo que um volume de experiência linguística, discursiva e literária anterior à leitura dessa obra lhe possibilitará penetrar mais profundamente nas sinuosas entrelinhas e nos infindáveis recursos da linguagem roseana. "O menino, timorato, aquietava-se com o próprio quebranto: alguma força, nele, trabalhava para arraigar raízes, aumentar-lhe alma” (GUIMARÃES, 2010, p. 18).

Figura 4 - As margens da alegria

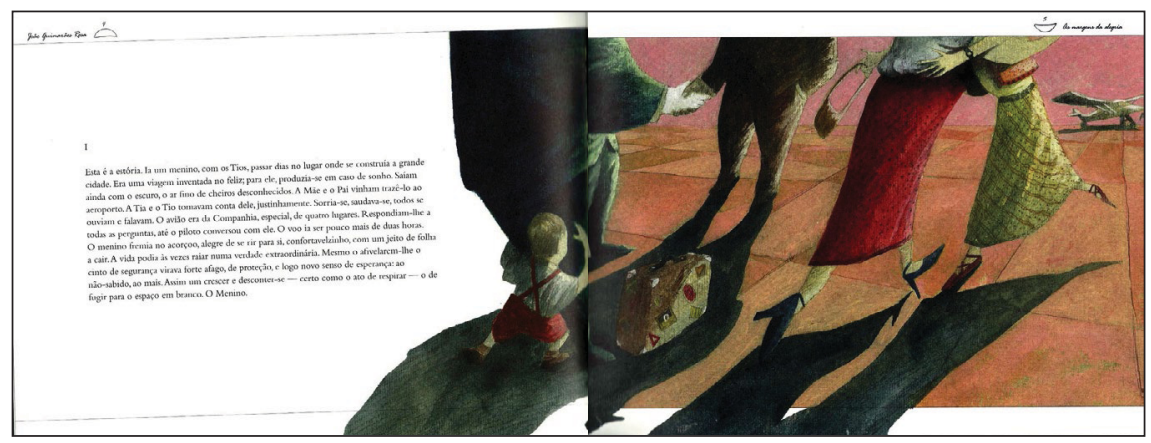

Fonte: Guimarães, 2010, p. 4-5.

Figura 5 - As margens da alegria

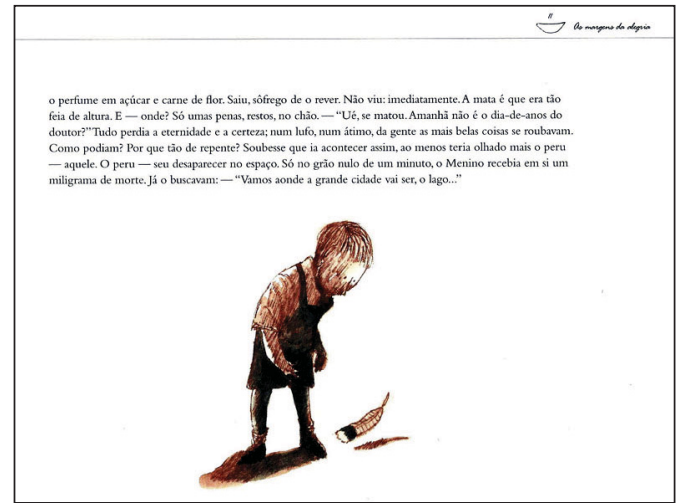

Fonte: Guimarães, 2010, p. 11.

PERSPECTIVA, Florianópolis, v. 30, n. 3, 843-868, set./dez. 2012

http://www.perspectiva.ufsc.br 
Figura 6 - As margens da alegria

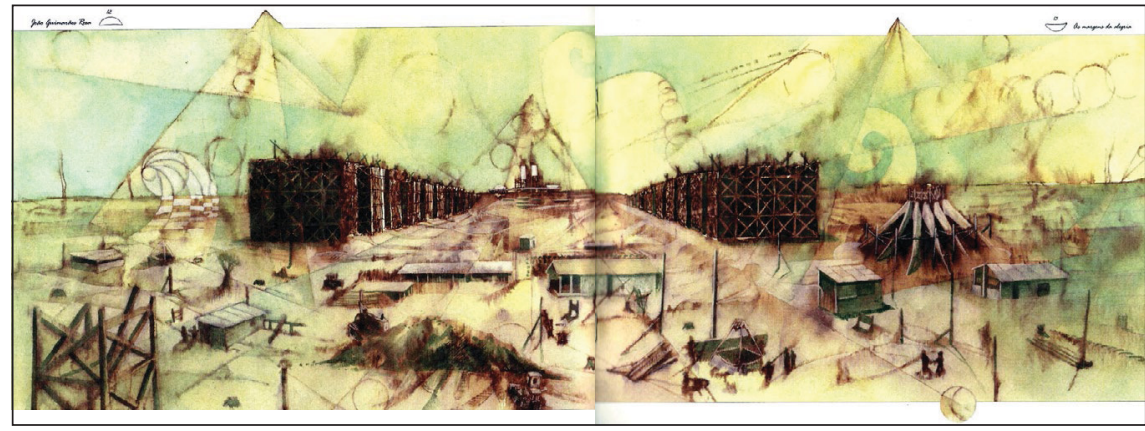

Fonte: Guimarães, 2010, p. 12-13.

Figura 7 - As margens da alegria

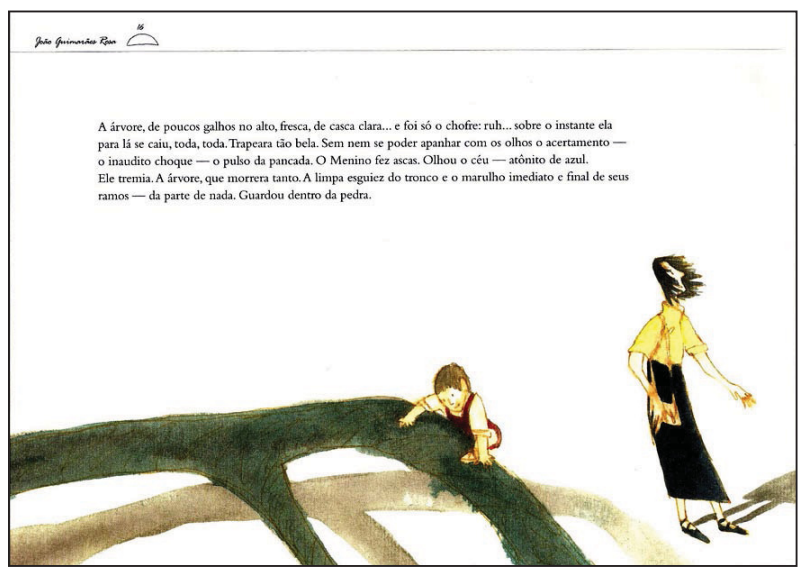

Fonte: Guimarães, 2010, p. 16.

\section{Considerações finais}

Pensar a o livro ilustrado contemporâneo é uma das grandes tarefas do nosso tempo. A importância de levar em consideração que as linguagens assumem novos formatos, criam novos gêneros, novos meios de expressão, que exigem novas habilidades cognitivas e, principalmente, denunciam a existência de novas subjetividades, novas formas de relação e interação é o dever de quem pretende se manter contatado com os leitores, com a formaçáo de leitores e com os mediadores. Dar voz à criança e ao jovem é o primeiro passo na direção de 
querer entender quais linguagens usam para, a partir de então, construir neles os leitores que desejamos.

Obras que vêm tratando a verbovisualidade como qualidade discursiva marcam fortemente o diálogo entre as funçôes de autor e de ilustrador; a liberdade com que os projetos editoriais apresentam a história a ser lida tende a recompor novos parâmetros conceituais para entender melhor os usos do espaço no desenvolvimento do enredo e indica a assunçấo dos novos parâmetros para a compreensão do que seja o livro ilustrado.

A superfície do papel deixa de ser um fundo vazio para instituir conteúdos, produzir significados, como nas duas obras citadas. As referências visuais exploradas nesses trabalhos muitas vezes servem para ratificar ou para desconstruir imagens previamente estabelecidas, como no caso da construção de Brasília, cidade sugerida pela ilustração à qual facilmente nos reportamos pelo seu desenho característico ou, ao contrário, na elaboração imaginária de personagens com cabeça de pássaro, que sufocavam a personagem Zolfe.

A dupla presença da linearidade verbal e da simultaneidade espacial apresenta novidades narrativas em relação ao modo de ler: a disposição e a quantidade de textos selecionados dependem da ilustraçáo da página, o que mostra a sua importância na composição do layout e na geração de camadas de leitura a serem percorridas por leitores: em Nenhum peixe aonde ir (HÉBERT, 2006), as personagens caminham sem saber seu destino com as figuras dispostas em círculo e a folha em branco; em As margens da alegria (GUIMARÃES, 2010), apenas o menino e uma pena, contendo todo o significado de uma ausência.

A edição de obras indicadas para jovens com elementos canônicos de literatura para crianças nos leva a pensar que não se trata de infantilização dos jovens ou mesmo de desatenção com a qualidade literária de que podem fazer uso, mas de entender que essas produções espelham a tensão por que vem passando a especificidade do discurso literário e, por outro lado, possibilidades da literatura para crianças e jovens.

A observação de que vivemos num momento de mudança de parâmetros, de tensão entre linguagens que se constituem e convivem em um mesmo espaço narrativo indica que esse é um debate contemporâneo e que se devem enfrentar questôes de fundo, como a instabilidade dos gêneros e dos seus diferentes usos. 


\section{Notas}

1 A distinçâo na literatura de língua inglesa entre picture books (livros com ilustraçôes) e picturebooks (livros ilustrados) sinaliza o aprofundamento de estudos nos usos das imagens em literatura infantil, nos últimos vinte anos.

2 Beckett (2012) amplia a ideia do trânsito de mão única de livros infantis e juvenis lidos por adultos. Os livros ilustrados, para ela, são um gênero que atravessa todas as idades.

3 Para maior aprofundamento do tema, ver Kac (2006).

\section{REFERÊNCIAS}

ABRAMOVICH, Fanny. O estranho mundo que se mostra às crianças. São Paulo: Summus, 1983.

ABRAMOVICH, Fanny. Literatura infantil: gostosuras e bobices. 5 ed. São Paulo: Scipione, 1995.

BAKHTIN, Mikhail. Estética da criação verbal. Tradução de francês de Maria Ermantina Galvão G. Pereira. São Paulo: Martins Fontes, 2000.

BECKETT, Sandra L. Crossover picturebooks: a genre for all ages. New York, London: Routledge, 2012.

CADEMARTORI, Lígia. O que é literatura infantil? São Paulo: Brasiliense, 1986.

CADEMARTORI, Lígia. O professor e a literatura: para pequenos, médios e grandes. Belo Horizonte: Autêntica, 2009.

CORTI, Ana Paula; SOUZA, Raquel. Aproximando-se do conceito de juventude. In: CORTI, Ana Paula; SOUZA, Raquel. Diálogos com o mundo juvenil: subsídios para educadores. São Paulo: Ação Educativa, 2004. p. 9-36.

CUNHA, Maria Antonieta. Literatura infantil: teoria e prática. São Paulo: Ática, 1983.

DAYRELL, Juarez. A escola "faz" as juventudes? Reflexôes em torno da socialização juvenil. Educação e Sociedade, Campinas, SP, v. 28, n. 100 - Especial, p. 1105-1128, out. 2007. Disponível em: <http://dx.doi. org/10.1590/S0101-73302007000300022>. Acesso em: 5 fev. 2012. 
GREGORIN FILHO, José Nicolau. Literatura infantil: múltiplas linguagens na formação dos leitores. São Paulo: Melhoramentos, 2009.

GOMBRICH, Ernst. Arte e Ilusão: um estudo da psicologia da representação pictórica. São Paulo: Martins Fontes, 1986.

HÉBERT, Marie-Francine. Nenhum peixe aonde ir. Ilustrações de Janice Nadeau. São Paulo: SM, 2006.

HUNT, Peter. Crítica, teoria e literatura infantil. Tradução de Cid Knipel. Sáo Paulo: Cosac Naify, 2010.

KAC, Eduardo. A questão da representação na holografia. In: FABRIS, Annateresa; KERN, Maria Lúcia Bastos (Org.). Imagem e conhecimento. São Paulo: Edusp, 2006. p. 227-254.

NIKOLAJEVA, Maria; SCOTT, Carole. Livro ilustrado: palavras e imagens. São Paulo: Cosac Naify, 2011.

PALLUY, Christine. Pequenos contos para sentir medo: histórias tradicionais de muitos lugares. Tradução de Heloisa Jahn. São Paulo: Cia. das Letrinhas, 2011.

PERROTI, Edmir. O texto sedutor na literatura infantil. São Paulo: Ícone, 1986.

PERROTI, Edmir. Confinamento cultural: infância e leitura. São Paulo: Summus, 1990.

POWERS, Alan. Era uma vez uma capa. Tradução de Otacílio Nunes. São Paulo: Cosac Naify, 2008.

ROSA, João Guimarães. As margens da alegria. Ilustrações de Nelson Cruz. Rio de Janeiro: Nova Fronteira, 2010.

SANDRONI, Laura. De Lobato a Bojunga. Rio de Janeiro: Agir, 1987.

SENDAK, Maurice. Onde vivem os monstros. São Paulo: CosacNaify, 2012. (primeira publicação americana em 1963)

SOSA, JESUALDO. A literatura infantil. São Paulo: Cultrix, 1980.

SPOSITO, Marília. Juventude e escolarização (1980/1998). n. 7. Brasília: MEC/INEP, Comped, 2002. (Série Estado do Conhecimento).

ZILBERMAN, Regina. A literatura infantil na escola. São Paulo: Global, 1981. 


\section{Le recit litteraire: un support pour l'enfance, un texte pour les jeunes}

\section{Résumé}

De nos jours, les livres de littérature pour enfants e constituent de trois dimensions: le texte, l'image et le format du support sur lequel se fondera la construction du récit. Toutefois, ces éléments peuvent aussi fausser ou transformer le profil desœuvres considérées canoniques pour les enfants, révélant ce qui est arbitraire dans ce modèle de livre. D'un autre coté, les narrations qui exploitent le texte verbal et le texte visuel en présupposant un jeune lecteur-modèle, et qui maintiennent le format de livre pour des enfants, indiquent que cette nouvelle génération d'adolescents se constitue de lecteurs qui utilisent des langages multiples et simultanées. Ce travail analyse les éléments-clés de la narration dans le livre Nul poisson où aller, de l'écrivaine franco-canadienne MarieFrancine Hébert, avec des illustrations de Janice Nadeau. La thématique de la guerre, sous les yeux de l'enfant et sous une forte présence de l'énonciation, permette des différents niveaux de lecture et de compréhension. Au même temps, l'utilisation d'images, de polices de caractères et de mise en page, que jadis indiquaient un enfant lecteur, comprennent actuellement une variété de lecteurs de différents publiques et d'âges diverses. L'oeuvre As margens da alegria, de Guimarães Rosa, avec des illustrations de Nelson Cruz, vise à s'opposer à

\section{Literary narrative: a foundation of childhood, text for youth}

\section{Abstract}

Contemporary children's literature is based on a tripod composed of text, image and support format to base the construction of the narrative. Nevertheless, these elements can also belie or transform the profile of works considered part of the canon for children, revealing the arbitrary nature of this model. Narratives that explore verbal and visual text aimed at youth readers and that maintain the format of a children's book indicate that adolescent readers use multiple and simultaneous languages. This study analyzes key elements of narrative in the book Nenhum peixe aonde ir, by French-Canadian author Marie-Francine Hébert, with illustrations by Janice Nadeau. The theme of war, from the perspective of the child and under a strong presence of enunciation, allows different layers of reading and comprehension. At the same time, uses of images, typefaces and layout, which in the past indicated a book was aimed at child readers, today contemplate a variety of readers of different publics and ages. The work As margens da alegria by Guimarães Rosa, with illustrations by Nelson Cruz, strives to counter some specificities of visual composition and text. Artistic categories (surface, image) and those from reading theory (model-reader, presupposition) help to understand this phenomenon 
certaines particularités de composition visuelle et textuelle. Quelques concepts empruntés aux arts plastiques (surface, image) et à la théorie de la lecture (lecteur-modèle, présupposition), nous aident à accéder à une compréhension de ce phénomène qui est devenu un modèle: le livre de littérature d'enfance et de jeunesse. Ainsi, on réévalue les conceptions habituelles sur la jeunesse et la lecture pour les jeunes, pour y intégrer d'autres formes de textes, et parmi elles, la littérature.

Mots-clés: Littérature pour l'enfance. Lecteurs. Illustration.

Celia Abicalil Belmiro

E-mail: celiab@terra.com.br that has become a model of literacy: the children's book. In this way, the concept of youth and reading for youth have been re-evaluated to include other forms of text and literature.

Keywords: Children's literature. Readers. Illustration.
Recebido em: 9/3/2012

Versão final recebida em: 28/11/2012

Aprovado em: 29/11/2012 